\title{
Aprendizado e engajamento social no ESDI / ReLab
}

\author{
Learning and social engagement of ESDI's ReLab
}

\author{
Valentina Kurkdjian Teixeira, Marina Araujo Scalabrin \& Helena de Barros
}

design de comunicação, ensino-aprendizagem, tecnologias digitais de informação e comunicação

Este artigo apresenta o acolhimento proporcionado aos estudantes ingressantes na Escola Superior de Desenho Industrial da UERJ por um laboratório remoto como alternativa complementar para o aprendizado e engajamento durante o isolamento. Esta análise foi feita através da observação do surgimento e funcionamento do ESDI ReLab: Laboratório Remoto de ensino-aprendizagem do Design, fruto da necessidade de pensar como o ambiente digital pode proporcionar aos alunos em contexto remoto uma experiência motivadora e estimulante como alternativa viável diante da impossibilidade do contato presencial na pandemia. Dá-se destaque ao aprofundamento da pesquisa e ao aprendizado do Design que esses estudantes tiveram através de um processo totalmente colaborativo.

communication design, teaching-learning, digital technologies information and communication

This article presents the provided welcoming to the first-year students at ESDI, Design School of Rio de Janeiro State University, by a remote laboratory as an additional alternative for the engagement and learning during the lockdown. This analysis was made by observing the arising and functioning of the ESDI ReLab: Remote Teaching-Learning Laboratory of Design, created from the need to think about how the digital environment can provide a motivating and stimulating experience that would be a viable alternative against the impossibility of face-to-face contact. This article highlights the deepening of Design research and learning that these students had through a fully collaborative process.

\section{Introdução}

Originário das mudanças de hábitos enfrentadas pelos estudantes que ingressaram na universidade no primeiro semestre de 2020, coincidentemente na véspera da instalação do isolamento social por conta do COVID-19, o ESDI ReLab: Laboratório Remoto de ensinoaprendizagem do Design é uma rede de professores e alunos voluntários da Escola Superior de Desenho Industrial da UERJ. Tem como objetivo estimular a produção e reflexão em design a serviço da sociedade e a troca de saberes por meio do uso de tecnologias remotas, operando-as colaborativamente.

O laboratório foi criado em consequência da suspensão das aulas para aquele semestre. Sem saber o que esperar quanto à nova realidade de ensino, esses estudantes, assim como estudantes de períodos avançados, aderiram voluntariamente à iniciativa de alguns professores de formar um grupo colaborativo de atividades. A primeira fase do projeto (na época

Anais do $10^{\circ} \mathrm{CIDI}$ e $10^{\circ} \mathrm{CONGIC}$

Kelli C.A.S. Smythe, Rafael de Castro Andrade (orgs.)

Sociedade Brasileira de Design da Informação - SBDI

Curitiba | Brasil | 2021
Proceedings of the $10^{\text {th }} \mathrm{CIDI}$ and $10^{\text {th }}$ CONGIC

Kelli C.A.S. Smythe, Rafael de Castro Andrade (orgs.)

Sociedade Brasileira de Design da Informação - SBDI Curitiba | Brazil | 2021 
ESDI/UERJ Quarentena) se concentrou na produção de peças de design de comunicação esclarecedoras sobre a prevenção do COVID-19. O laboratório se consolidou oficialmente em agosto de 2020 como um projeto de extensão, ao mesmo tempo em que foram retomadas aulas remotas no contexto do Período Acadêmico Emergencial (PAE). Tem o propósito de praticar, propor e experimentar diferentes formas de ensinar e aprender Design através do uso das Tecnologias Digitais de Informação e Comunicação (TDICs), auxiliando no desenvolvimento de competências complementares ao curso, além de favorecer trocas e a sociabilidade entre alunos e professores através de interação remota.

\section{Os preceitos das pedagogias decoloniais para o protagonismo do aluno}

Orientado a partir da noção de educação problematizadora (Freire, 2011), no sentido de promover a autonomia dos educandos, o projeto é também norteado por uma perspectiva decolonial (Walsh, 2017) questionando a matriz europeia que por muito tempo serviu de modelo para o ensino de design. Esses fundamentos teóricos foram utilizados através da abordagem do Design Participativo, que propõe discutir as funções e repensar a participação dos agentes no processo projetual.

O ESDI/ReLab faz uso de canais de comunicação gratuitos e acessíveis como o Discord e o Whatsapp. Considera-se que todos os membros envolvidos têm pontos importantes para agregar ao projeto, podendo ser proponentes de soluções para as diferentes tarefas. Esses canais colaboram na divisão de grupos de trabalho e reuniões, pelos canais de voz ou videoconferência.

Para o professor Ricardo Artur Carvalho, o ESDI/ReLab oferece oportunidades circunstanciais de orientação e aprendizado, exemplificado aqui em mensagem de texto sobre a diferença entre quebra de linha e de parágrafo (figuras 1 e 2), em que o professor sugeriu que os estudantes experimentassem essas técnicas de diagramação. $O$ aprendizado ocorre de acordo com as situações experimentadas, invertendo a lógica de um plano de estudos pré-definido (Carvalho, 2021). 
Figura 1: Captura de tela da conversa entre aluna e professor no grupo de WhatsApp do ESDI/ReLab esclarecendo sobre os métodos de alinhamento de texto de um post (uso permitido pelos autores).

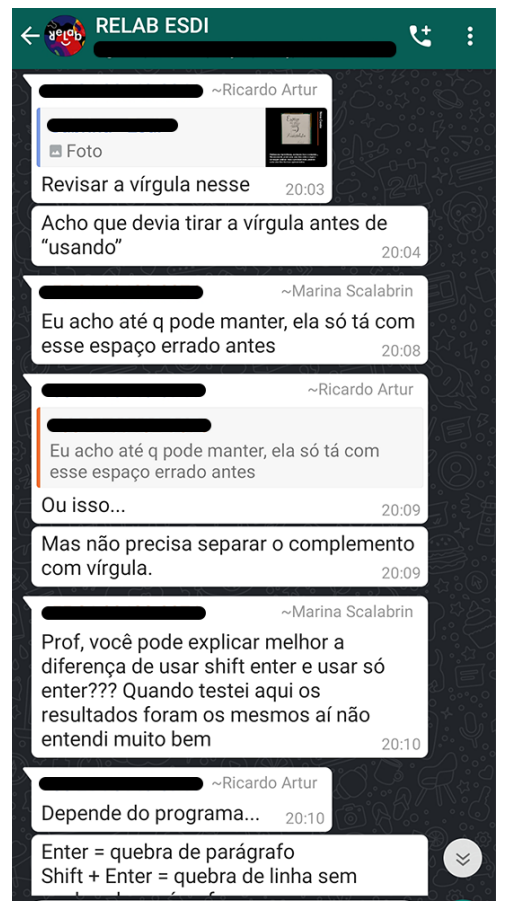

Figura 2: (Cont.) Captura de tela da conversa entre aluna e professor no grupo de WhatsApp do ESDI/ReLab esclarecendo sobre os métodos de alinhamento de texto de um post (uso permitido pelos autores).

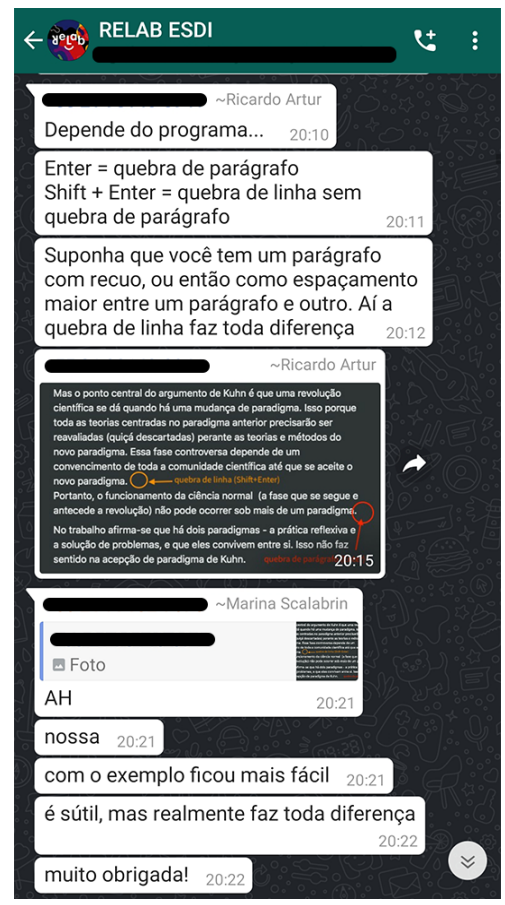




\section{Planejamento e estratégia metodológica}

As ações são planejadas a partir da criação de um cronograma mensal de conteúdos que investiguem formas autônomas de atuação dos estudantes de design como sujeitos de sua própria aprendizagem e formação. Para fins organizacionais, existem grupos de trabalho específicos, que se dividem em diferentes atividades: planejar e gerenciar os conteúdos das redes sociais, fazer o design das postagens, criar e editar vídeos, planejar a logística das atividades, estabelecer a comunicação com os participantes e avaliar as atividades oferecidas, entre outros. Os membros do ReLab (atualmente 31 estudantes) se inserem nos grupos de trabalho a partir de seus interesses naturais e competências, e têm a oportunidade de ter contato com tudo que é feito, opinar e aprender com cada processo, promovendo aquisição de conhecimento em diversas áreas do design de comunicação.

São também realizadas oficinas que promovam trocas de conhecimento entre alunos, professores e membros externos da comunidade. Utilizam-se os benefícios das mídias sociais, principalmente os do Instagram e YouTube, para tornar público os conteúdos planejados.

As atividades são supervisionadas e estimuladas por 4 professores, a partir de consenso sobre os conteúdos a serem desenvolvidos, indicação de soluções técnicas e sua adequação ao contexto da universidade pública. São incentivadas trocas de saberes e expertises através de pedagogias horizontais, promovendo a iniciativa e autonomia progressiva dos estudantes na proposição e solução de tarefas.

A cada ação, os resultados são reavaliados considerando o rendimento pessoal de cada um e oportunidades de ações futuras.

\section{Resultados alcançados}

Os preceitos, estratégias e planejamentos praticados estruturam um caminho sólido para a experimentação dos universitários com o Design. É perceptível a importância que o projeto conquistou como um espaço seguro para a formação e aprimoramento das habilidades desses estudantes, que exploram diversas competências acadêmicas, pessoais, profissionais e sociais, enquanto colaboram entre si.

Os resultados dessa troca puderam ser observados logo no início do projeto, quando muitas peças gráficas para redes sociais sobre conscientização em relação ao COVID-19 foram feitas por alunos com pouco ou nenhum contato prévio com softwares de criação. Elas eram elaboradas individualmente ou em grupos de 2 a 3 pessoas, enquanto todos os envolvidos no projeto auxiliavam, por exemplo, com dicas sobre o uso dos programas, ensinamentos de conceitos como diagramação e Gestalt, ou sugestões de possíveis melhorias. Obteve-se um excelente alcance com essas postagens, especialmente no Instagram, onde os posts melhor repercutiram. Algumas dessas peças foram produzidas em parceria com outras unidades da UERJ, como o Instituto de Química ou o Hospital Universitário Pedro Ernesto.

Quando o grupo se consolidou como projeto de extensão - ReLab, a criação de sua identidade visual foi feita inteiramente pelos integrantes. Isso permitiu mais uma série de aprendizados 
pelo desenvolvimento do logo e suas versões, paleta de cores, padronagens, vinheta animada e uma série de postagens explicando os processos dessa criação colaborativa. Foi desenvolvida também a identidade visual para o grupo CURA: Cultura Urbanismo Resistência Arquitetura (laboratório do curso de Arquitetura da ESDI/UERJ). As identidades foram desenvolvidas colaborativamente na integração remota de vários alunos, comunicando-se e compartilhando conteúdo através de diversas plataformas digitais.

Workshops viabilizam conteúdos mais complexos e práticos e divulgam o projeto fora da comunidade da ESDI-UERJ. Nosso primeiro Workshop foi oferecido por uma caloura, ingressante na véspera da quarentena, e o último, por um doutorando da pós-graduação da Escola. O trabalho realizado, citado acima, surgiu da necessidade de repensar o aprendizado da universidade, em consequência de sua estrutura curricular ser centralizada em disciplinas obrigatórias, o que faz com que a posição e autoridade dos professores se reafirme. Desse modo, identificamos que a carência de autonomia nessa estrutura não colabora para os alunos traçarem suas próprias trajetórias de modo que consigam se aprofundar em temas e discussões que considerem relevantes. Com isso, os Workshops possuem o intuito de irem na direção oposta dos paradigmas tradicionais já impostos, se direcionando para uma descolonização das relações de poder e de conhecimento da organização acadêmica (Walsh, 2017).

Ambos os eventos destacaram a importância do debate, consciência, união coletiva e chances de aprimoramento (Gonçalves; Moreira, 2021). As ações integram, portanto, estudantes de diversos períodos e níveis de especialização, que sequer tiveram a chance de se conhecer pessoalmente, mas valorizam a troca de saberes. As oficinas abertas são ministradas gratuitamente por videochamada para todos os interessados, e garantem certificação de horas complementares de atividades acadêmico-científico culturais. 
Figura 3: Imagem de divulgação do Workshop de Lettering, onde ensinou sobre os princípios básicos do lettering. Ministrada por uma bacharelanda da ESDI/UERJ. (arte feita por Rafael Inocencio, aluno da ESDI/UERJ, uso permitido pelo autor)

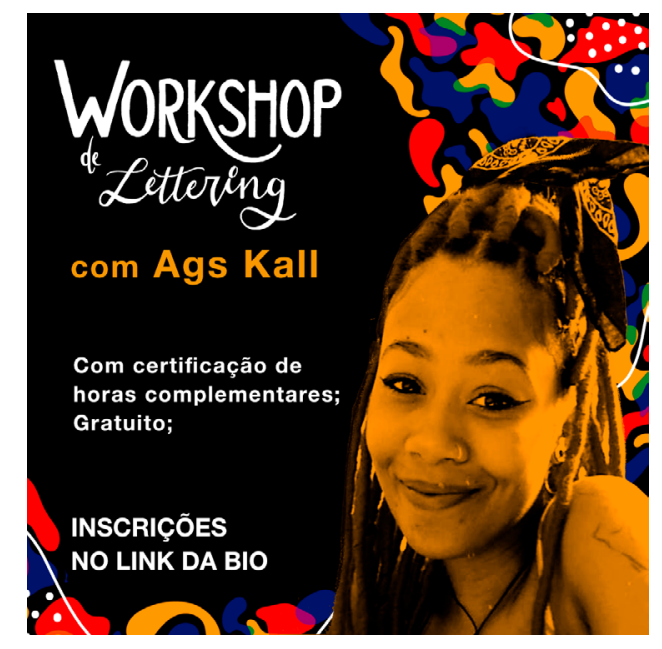

Figura 4: Imagem de divulgação do Workshop Design Vs. Calote, onde ensinou sobre prestação de serviços como autônomo e o que precisa fazer para se estar sempre protegido. Ministrada por um doutorando da ESDI/UERJ. (arte feita por Ana Mel Naciff, aluno da ESDI/UERJ, uso permitido pelo autor)

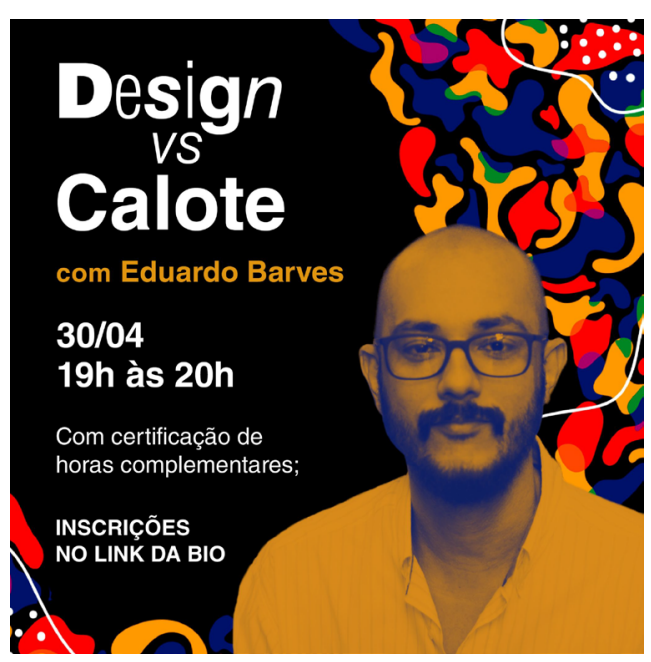

\section{Ação transformadora do projeto}

Como argumenta Necyk (2013), o uso das tecnologias digitais de informação e comunicação como facilitador nas práticas de ensino na graduação em Design tem um significado que vai além da tecnologia em si. Em uma sociedade mediada pela tecnologia, seu uso também acentua a noção de pertencimento, possibilitando que grupos de pessoas tão diversas se unam, mesmo a muitos quilômetros de distância.

O laboratório possibilitou a sensação de acolhimento tanto através da interação social entre alunos de diferentes turmas e destes com professores, como também da soma de pósgraduandos compartilhando suas experiências e estudos. Esse câmbio e aprendizado mútuo 
fomentados por rodas de conversa, reuniões e workshops, trazem benefícios para os estudantes que ultrapassam as fronteiras da sala de aula.

Através de depoimentos coletados, os estudantes descreveram que tal aspecto os impulsionou a aprender coisas novas e temas relevantes, transmitir informações úteis para seus colegas, colocar em prática aprendizados prévios e esclarecer dúvidas de uma forma mais casual. Também foi dito que essa experiência os fez valorizar mais o designer como profissional "ativo e com voz, responsável por passar informação e somar com pensamento crítico" (Loureiro, 2021), por ser um local amistoso onde todos são levados em conta para opinar e somar. E partindo desses aprendizados, uma estudante que participou no desenvolvimento da identidade visual do projeto, cita: "tive a oportunidade de absorver diversos conhecimentos que foram um diferencial no meu currículo e portfólio para a conquista de uma vaga de trabalho" (Pessoa, 2021).

\section{Considerações finais}

Este artigo demonstra de forma concisa o objetivo do ESDI/ReLab de viabilizar a autonomia dos estudantes e os meios utilizados para tal, bem como a elaboração de projetos que permitam a abertura de visão para novas oportunidades. Possibilitando também aos alunos a chance de se conscientizarem de modo reflexivo sobre seus próprios processos; descobrindoos, manifestando-os e configurando-os (Freire, 2011, p.10).

Como afirma Necyk (2013), a análise do uso e da percepção de tecnologias digitais de informação e comunicação pode indicar questões a serem revistas quanto ao ensino, somadas à possibilidade de discutir aspectos sociais mais abrangentes.

Nota-se que a pandemia pegou todos desprevenidos, inclusive o sistema público de ensino que ainda não tinha tido a oportunidade de experimentar tão intensamente tais possibilidades remotas de ensino/aprendizagem. Assim, o isolamento social foi uma medida necessária e extremamente impactante, mas que abriu novas possibilidades e reflexões sobre modelos de ensino e o acesso digital.

- $\quad$ todas as imagens e depoimentos foram reproduzidos com autorização dos autores.

\section{Referências}

Carvalho, Ricardo Artur; Gonçalves, Eduardo; Inocencio, Rafael; Loureiro, Felipe; Machado, Lucas; Moreira, Aghata; Pessoa, Maria Eduarda. [depoimentos]. WhatsApp: [mensagens pessoais] Depoimentos concedidos às autoras via WhatsApp. Rio de Janeiro, 11-13 mai. 2021.

Couto, Rita., et al. (Org.). (2014). Design em Situações de Ensino-Aprendizagem: 20 anos de pesquisa no Laboratório Interdisciplinar de Design/Educação. 1ed. Rio de Janeiro: Rio Book's, 2014, v. 1, p. 20-76. 
Martins, Bianca. (2018). Discursos orientadores do uso do Design em práticas educativas. Revista Carioca de Ciência, Tecnologia e Educação (online). Rio de Janeiro: v. 3 | n. 1, 2018.

Necyk, Barbara Jane. (2013). Usos e sentidos de tecnologias digitais de informação e comunicação em contextos de ensino-aprendizagem no Design. Tese de Doutorado. Rio de Janeiro, Programa de Pós-graduação em Design, Departamento de Artes \& Design, PUCRJ, 2013.

Freire, Paulo. (2011). Pedagogia do Oprimido. Rio de Janeiro: Paz e Terra, 2011.

Walsh, Catherine. (2017). Pedagogías Decoloniales. Práticas Insurgentes de resistir, (re)existir e (re)vivir. Série Pensamiento Decolonial. Editora Abya-Yala. Equador, 2017.

\section{Sobre as autoras}

Valentina Kurkdjian Teixeira, Bacharelanda, ESDI/UERJ, Brasil, <valentinakt2000@gmail.com> Marina Araujo Scalabrin, Bacharelanda, ESDI/UERJ, Brasil, <marina.scalabrin@gmail.com> Helena de Barros, Dsc, Professora Adjunta ESDI/UERJ, Brasil <helenbar@esdi.uerj.br> 